\title{
RS-based Quantitative Evaluation on the Service Value of the Ecological System in Lijiang River Basin
}

\author{
Ning $\mathrm{Li}^{1,3}$, Jinye Wang ${ }^{2}$, and Haoyu Wang ${ }^{2,3, *}$ \\ ${ }^{1}$ Bowen College of Management Guilin University of Technology, Guilin 541006, China \\ ${ }^{2}$ Guilin University of Technology, Guiling 541006, China \\ ${ }^{3}$ Key Laboratory of spatial information and mapping of Guangxi, Guilin 541006, China
}

\begin{abstract}
The ecological system service is closely related to the citizens' welfare and serves as the bridge connecting the ecological system and the social system. To achieve sustainable development, we must protect the ecological environment. The paper marks off different land utilization types of the Lijiang River basin based on the remote sensing technique, and borrows ideas from other research findings and combines the practical situation of Lijiang River basin to correct the service unit price of ecological system type of the Lijiang River basin, then calculates the service value of ecological system for the basin in turn. The findings show that the total value of the service function of ecological system for the Lijiang River basin is $7195.22 \times 10^{6}$ Yuan. In terms of the service function of the ecological system, the woodland's service function value accounts the largest proportion in the whole ecological system, being $85.26 \%$ of the total value. In terms of the service function type of the ecological system, the soil formation and protection are the most significant, with value of $1340.00 \times 10^{6}$ Yuan, which accounts for $18.62 \%$. The ecological service value's sequence in ascending order is: Food production $<$ entertainment culture $<$ raw material $<$ waste disposal $<$ climate regulation $<$ gas conditioning $<$ biological diversity protection $<$ headwater conservation $<$ soil formation and protection. The research is of important theoretical guidance and practical meaning for the monitoring over the ecological environment of Lijiang River basin and the sustainable development of tourism.
\end{abstract}

\section{Introduction}

The service function of the ecological system refers to the natural environmental conditions and effectiveness which are formed and maintained by the ecological system and the ecological process and vital to humans' surviva ${ }^{[1-2]}$. The ecological system service is closely related to the citizen's welfare and serves as bridge connecting the ecological system and the social system ${ }^{[3-}$ 4]. The changes in land use transform the original service functions of the ecological system, so to research the service function of ecological system from the angle of land use is of important significance for cognizing the relation between humans and the nature ${ }^{[5]}$. The population growth and urbanization produce a negative effect on the ecological system ${ }^{[6]}$. The Lijiang River basin is the gold thoroughfare for the world renowned resort and the main water-supply source for Guilin. This lifeline of Guilin has an important status in the ecological and economic domain, being one of key rivers protected by the state ${ }^{[7-8]}$. With the acceleration of urbanization, swift growth of population and instant development of the tourism in this basin in the last decades, the land use pattern of the Lijiang River basin has changed largely, such as increasingly longer lowwater season, accelerated exacerbation of aquatic environment and ecological environment ${ }^{[9-10]}$. Currently scholars have made preliminary studies on the Lijiang River basin, finding that the changes of land use significantly influenced the physical properties of the moisture in the topsoil of basin and its spatial variation ${ }^{[8]}$. The land use of the Lijiang River basin changed greatly in last two decades, such as obvious degradation of wooded area with important ecological functions, everincreasing of the proportion of construction land and farmland ${ }^{[9]}$, leading to the trend of decline in the service value of ecological system in the future ${ }^{[11]}$. The Lijiang River basin lies in the upstream of the Zhujiang River Basin. As the mother river of Guilin, the Lijiang River nurtures over 2 million citizens in Guilin, being an important guarantee for the economical and social development of Guilin and Xijiang River Basin. This lifeline for the survival of Guilin tourism is an important foundation for the construction of national pilot area of comprehensive tourism reform, yet currently there is devoid of evaluation on the service value of the Lijiang River basin's ecological system using the remote sensing technique. In addition, Guilin is just in the critical period for construction of an international tourism resort and healthy tourism, so quantitative evaluation on the service value of the ecological system can provide a scientific

\footnotetext{
*Corresponding author: haoyu@glut.edu.cn
} 
basis and important reference for the ecological compensation.

\section{General situation of region of interest}

The Lijiang River basin, which is governed by Guilin, is located in the northeast of Guangxi Zhuang Autonomous Region. It is rooted in Maoershan Mountain, the top peak in South China, and its trunk streams pass Xing'an, Lingchuan, Guilin urban area, Yangshuo and Pingle, then flows into Guijiang River. With a total length of $214 \mathrm{~km}$ from the source of the Lijiang River to Pingle, it is between east longitude $110^{\circ} 07^{\prime} 39^{\prime \prime}-110^{\circ} 42^{\prime} 57^{\prime \prime}$ and north latitude $24^{\circ} 38^{\prime} 10^{\prime \prime}-25^{\circ} 53^{\prime} 59^{\prime \prime}$ (Fig. 1 ).

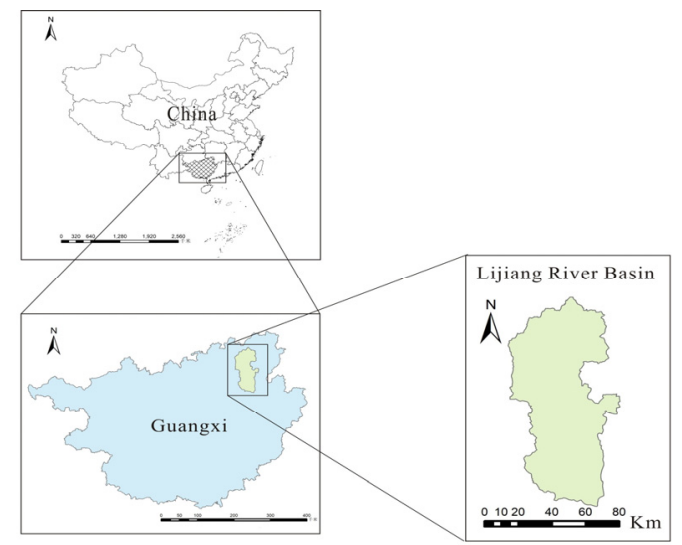

Fig. 1.The region of interest.

The side banks for the Yangshuo segment of the Lijiang River is the most typical karst fungling relief in the world. The Lijiang River has nearly 30 branches. The Lijiang River basin belongs to the central Asian tropical monsoon climate zone, and the area of Huajiang River, ChuanjiangRiver, Yantian, Shangdong and Gaozhai in the upstream of Lijiang River is one of high-value regions with rainstorm, with good growth conditions for forest. The Lijiang River basin concentrates the tourism resources of Guilin and is rich in tourism resources, and the famous Guilin Landscape is just located on the Lijiang River. The basin is a typical area boosting the regional economy ${ }^{[12]}$. The Lijiang River is a rain-sourced river, which has hugely different runoff in the rainy season and the dry season despite the abundant precipitation and rich water flow, the annual distribution of runoff is very disproportional, as more than $85 \%$ of precipitation is concentrated in the period from April to August each year.

\section{The data source and research technique}

\subsection{Data source}

The basin boundary was extracted using the digital elevation model for the Lijiang River basin. The Landsat8 remote sensing data with cloudage less than $10 \%$ in 2017 was downloaded from United States Geological Survey. The ENVI5.3 and ARCGIS10 were used to process the images. The Google Earth was used for monitoring classification. The hand-held GPS was used for field test on the samples. Four land ecotypes of farmland, woodland, water area and artificial surface were divided into (Fig.2) and the area for land types was tallied (Table 1). By combining the characteristics of the ecological system of earth in the Lijiang River basin, the service functions of the ecological system of different land types in the Lijiang River basin were divided into nine ones ${ }^{[13-15]}$.

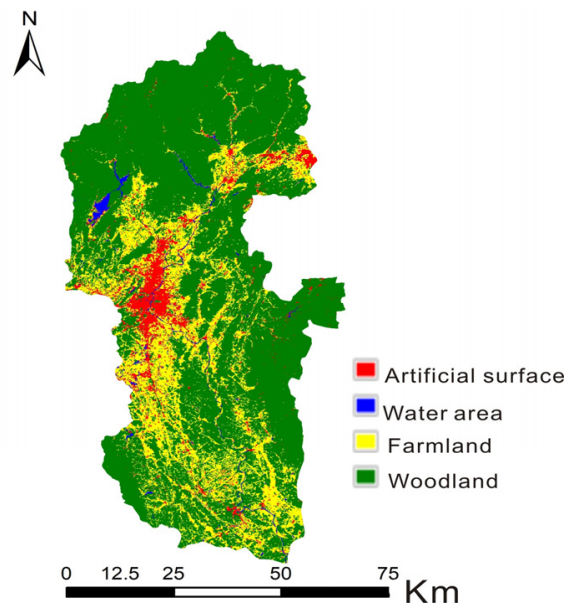

Fig.2.The classification map for remote sensing images for the land use in the Lijiang River basin.

Table 1.The area of ecological systems of different types in the Lijiang River basin.

\begin{tabular}{ccc}
\hline Land use type & Area $\left(\mathrm{hm}^{2}\right)$ & $\begin{array}{c}\text { Proportion of } \\
\text { area (\%) }\end{array}$ \\
\hline Artificial & 37095.48 & 6.36 \\
surface & 6787.35 & 1.16 \\
Water area & 130972.59 & 22.46 \\
Farmland & 408280.68 & 70.02 \\
Woodland & 583136.10 & 100 \\
Total & & \\
\hline
\end{tabular}

\subsection{Calculation method of the service value of ecological system}

The paper adopts the value accounting method to analyze the service value of the ecological system in the Lijiang River basin, as shown in equation (1).

$$
E S V=\sum_{i}^{4} \sum_{j=1}^{9}\left(S_{i} \times \mathrm{V} \mathrm{C}_{i j}\right)
$$

Where, $\mathrm{S}_{\mathrm{i}}$ represents the area of type-i ecological land, $\mathrm{VC}_{\mathrm{ij}}$ represents the service value of the type-j ecological system for the unit earth area of type-i, and ESV represents the gross service value of the ecological system in the Lijiang River basin.

Based on the service value of the unit area of Chinese terrestrial ecosystem ${ }^{[13]}$ (table 2 ) and borrowing ideas from other research findings, the unit price of service for the ecosystem-type in the region of interest is corrected, to derive the service value of the unit area of ecological system in the Lijiang River basin (table 3). By referring to the state land use classification system and combining 
the physical circumstances of the Lijiang River basin, each land use type is correlated to the closest ecosystemtype in the table of ecological system service value as specified by Xie Gaodi, et al. Wherein, the service value of artificial surface ecological system is 0 , the value for the woodland is set as the average value for the weight of 2 for the forest and weight of 1 for the meadow, and the farmland corresponds to the farm field. After

Table 2. The ecological service value for unit area of different terrestrial ecosystems in China $\left(\mathrm{Yuan} / \mathrm{hm}^{2}\right)$.

\begin{tabular}{cccc}
\hline \multirow{2}{*}{$\begin{array}{c}\text { Service function of } \\
\text { ecological system }\end{array}$} & Woodland & Farmland & Water area \\
\cline { 2 - 4 } & 2300.63 & 433.55 & 0.00 \\
Gas conditioning & 1858.20 & 771.75 & 407.00 \\
Climate control & 2123.63 & 520.28 & 18033.20 \\
Headwater conservation & 2875.77 & 1266.06 & 8.80 \\
Soil formation and protection & 1159.20 & 1422.17 & 16086.60 \\
Waste disposal & 2244.57 & 615.64 & 2203.30 \\
Biological diversity & 147.50 & 867.20 & 88.50 \\
protection & 1548.47 & 86.73 & 8.80 \\
Food production & 766.87 & 8.62 & 3840.20 \\
Raw materials & 15024.84 & 5992.00 & 40676.40 \\
Entertainment culture & & &
\end{tabular}

correcting of the unit price of service value for the ecological system[13-14,16], its service values of ecological system is derived. Due to the uncertainty of evaluation indices ${ }^{[17]}$, the paper corrects the ecological service value and the ecological service unit price based on the

Table 3. The ecological service value for unit area of ecological system in Lijiang River basin (Yuan/hm2).

\begin{tabular}{cccc}
\hline $\begin{array}{c}\text { Service function } \\
\text { of ecological } \\
\text { system }\end{array}$ & Woodland & Farmland & Water area \\
\cline { 2 - 4 } & 2300.63 & 433.55 & 0.00 \\
\hline Gas conditioning & 1858.20 & 771.75 & 407.00 \\
Climate control & 2123.63 & 520.28 & 18033.20 \\
$\quad \begin{array}{c}\text { Headwater } \\
\text { conservation }\end{array}$ & 2875.77 & 1266.06 & 8.80 \\
$\begin{array}{c}\text { Soil formation } \\
\text { and protection }\end{array}$ & 1159.20 & 1422.17 & 16086.60 \\
Waste disposal & & & \\
Biological & 2244.57 & 615.64 & 2203.30 \\
$\quad$ diversity & & 867.20 & 88.50 \\
protection & 147.50 & 86.73 & 8.80 \\
Food production & 1548.47 & 8.62 & 3840.20 \\
Raw materials & 766.87 & 5992.00 & 40676.40 \\
Entertainment & culture & &
\end{tabular}

hypothesis that the strength of ecological service function is in a linear relation with the biomass, as shown in equation (2).

$$
V C_{i j}=\left(b_{i} / B\right) R_{i j}
$$

Where, $\mathrm{VC}_{\mathrm{ij}}$ represents the corrected ecological service value for the unit area of ecological system, i.e. the service value of type-j ecological system for the type-i unit area of land, i represents the four ecological types of forest, artificial surface, water, farmland, $\mathrm{j}=1,2,3 \cdots, 9$ respectively represents different service functions of ecological system of gas conditioning and climate control, etc.; $b_{i}$ represents the biomass of type- $i$ ecological system, $\mathrm{B}$ is the average biomass in unit area of China's grade-1 ecological system. $R_{i j}$ is the benchmark unit price for the type-j ecological service function for unit area of type-i ecological system. The biomass factor for national farm field ecological system is 1 . The biomass factor for the farm filed in the Lijiang River basin is set as 0.98 , the mean of Guangxi, i.e. $\mathrm{VC}_{\mathrm{ij}}=(0.98 / 1.00) \mathrm{R}_{\mathrm{ij}}, \mathrm{VC}_{\mathrm{ij}}=0.98 \cdot \mathrm{R}_{\mathrm{ij}}$.

\section{The evaluation and analysis on the service value of ecological system in the Lijiang River basin}

According to the remote sensing imagery interpretation result and the area of land use type in Lijiang River basin and by combining the corrected service unit price of ecological system types for the basin, the service value of the ecological system in the Lijiang River basin is estimated (table 4). The result

Table 4.The service value of ecological system in the Lijiang River basin.

\begin{tabular}{|c|c|c|c|c|c|}
\hline \multirow{2}{*}{$\begin{array}{l}\text { Service } \\
\text { function of } \\
\text { ecological } \\
\text { system }\end{array}$} & \multicolumn{3}{|c|}{$\begin{array}{l}\text { Service function value of } \\
\text { ecological system }\left(10^{6} \text { Yuan }\right)\end{array}$} & \multirow{2}{*}{$\begin{array}{c}\text { Total } \\
\left(10^{6} \text { Yuan }\right)\end{array}$} & \multirow{2}{*}{$\begin{array}{c}\text { Proporti } \\
\text { on }(\%)\end{array}$} \\
\hline & Woodland & $\begin{array}{l}\text { Farm } \\
\text { land }\end{array}$ & $\begin{array}{l}\text { Water } \\
\text { area }\end{array}$ & & \\
\hline $\begin{array}{c}\text { Gas } \\
\text { conditioning }\end{array}$ & 939.30 & 56.78 & 0 & 996.09 & 13.84 \\
\hline $\begin{array}{l}\text { Climate } \\
\text { control }\end{array}$ & 758.67 & 101.09 & 2.76 & 862.51 & 11.99 \\
\hline $\begin{array}{l}\text { Headwater } \\
\text { conservation }\end{array}$ & 867.03 & 68.14 & 122.40 & 1057.58 & 14.70 \\
\hline $\begin{array}{c}\text { Soil } \\
\text { formation } \\
\text { and } \\
\text { protection }\end{array}$ & 1174.12 & 165.82 & 0.06 & 1340.00 & 18.62 \\
\hline $\begin{array}{l}\text { Waste } \\
\text { disposal }\end{array}$ & 473.28 & 186.27 & 109.19 & 768.73 & 10.68 \\
\hline $\begin{array}{l}\text { Biological } \\
\text { diversity } \\
\text { protection }\end{array}$ & 916.41 & 80.63 & 14.95 & 1012.00 & 14.06 \\
\hline $\begin{array}{l}\text { Food } \\
\text { production }\end{array}$ & 60.22 & 113.58 & 0.60 & 174.40 & 2.43 \\
\hline $\begin{array}{c}\text { Raw } \\
\text { materials }\end{array}$ & 632.21 & 11.36 & 0.06 & 643.62 & 8.95 \\
\hline $\begin{array}{l}\text { Entertainmen } \\
\mathrm{t} \text { culture }\end{array}$ & 313.10 & 01.13 & 26.06 & 340.29 & 4.73 \\
\hline $\begin{array}{l}\text { Total(106 } \\
\text { Yuan) }\end{array}$ & 6134.34 & 784.80 & 276.08 & 7195.22 & 100 \\
\hline $\begin{array}{l}\text { Proportion in } \\
\text { the total } \\
\text { value }(\%)\end{array}$ & 85.26 & 10.90 & 3.84 & 100 & \\
\hline
\end{tabular}

shows that the total service value of the ecological system in Lijiang River basin in 2017 was $7195.22 \times 10^{6}$ Yuan. In terms of service function types of the ecological system, the soil formation and protection was 
the most significant, with value of $1340.00 \times 10^{6}$ Yuan, which accounted for $18.62 \%$; the headwater conservation function came the second, with value of $1057.58 \times 10^{6}$ Yuan, which accounted for $14.70 \%$; the value of biological diversity protection was $1012.00 \times 10^{6}$ Yuan, which accounted for $14.06 \%$; the value of gas conditioning was $996.09 \times 10^{6}$ Yuan, which accounted for $13.84 \%$; the value of climate control was $862.51 \times 10^{6}$ Yuan, which accounted for $11.99 \%$; the value of waste disposal was $473.28 \times 10^{6}$ Yuan, which accounted for $10.68 \%$; in addition, the values of food production, raw materials and entertainment culture were respectively $174.40 \times 10^{6}$ Yuan, $643.62 \times 10^{6}$ Yuan and $340.29 \times 10^{6}$

Yuan, which respectively accounted for $2.43 \%, 8.95 \%$ and $4.73 \%$. In terms of the service function value of ecological system of the land types, the wooded land was the most significant, with value of $6134.34 \times 10^{6}$ Yuan, which accounted for $85.26 \%$. The farmland and water area came the second, with value of $784.80 \times 10^{6}$ Yuan and $276.08 \times 10^{6}$ Yuan, which accounted for $10.90 \%$ and $3.84 \%$ respectively.

\section{Conclusions and discussion}

(1) The unit price of ecological system types for the Lijiang River basin is corrected by referring to the domestic and foreign method of ecological system service value. The service value of the ecological system in the Lijiang River basin is calculated by combining the remote sensing data. In terms of land use types, the wooded land ranks the first, with an area of 37095.48 $\mathrm{hm}^{2}$, then the farmland, artificial surface and water area come the second, with area of $6787.35 \mathrm{hm}^{2}, 130972.59$ $\mathrm{hm}^{2}$ and $408280.68 \mathrm{hm}^{2}$ respectively. In terms of the service functions of the ecological system, the wooded land accounts for the largest proportion in the service function value of the whole ecological system, being $85.26 \%$. Besides, the result of remote sensing land type interpretation shows that the wooded land is more concentrated in the source of the Lijiang River. Thus, the protection for the wooded land in this basin appears allimportant. The future management should enhance the research on the process and service of the ecological system in the Lijiang River basin.

(2) In terms of the importance of ecological system service functions, food production $<$ entertainment culture $<$ raw materials $<$ waste $\quad$ disposal $<$ climate control $<$ gas conditioning $<$ biological diversity protection $<$ headwater conservation $<$ soil formation and protection, while the value of raw materials and food production only account for $11.38 \%$ of total value, indicating that the indirect service value of ecological system accounts for a larger proportion, and such indirect value is prone to be ignored. The entertainment service accounts for only $4.73 \%$. The Lijiang River basin is an important tourism destination with booming tourism, so the entertainment service which is an important index for tourism supply should be valued. Therefore, we should pay attention to the environmental protection while developing the resources, to raise the utilization efficiency of tourism resources, and make scientific planning and effective management of the natural reserves.

(3) The paper makes a comprehensive and quantitative evaluation on the service value of ecological system in the Lijiang River basin, thereby providing more comprehensive scientific basis and decisionmaking support for the evaluation on the natural assets and ecological compensation in the basin. The research is of important theoretical guidance and practical significance for the monitoring over the ecological environment in the Lijiang River basin and the local sustainable development.

\section{Acknowledgment}

This work was supported by the National scientific and technological support projects (2012BAC16B04), the Guangxi education department youth teacher basic ability improvement project (2017KY1360) and GuangXi Key Laboratory of Spatial Information and Geomatics Program (Contract No. GuiKeNeng 151400734, 163802518 and 163802531).

\section{References}

1. Daily G C. Nature's services: societal dependence on natural ecosystems. Washington D C: Island Press, 1997

2. OuYang Zhiyun, Wang Rushong, Zhao Jingzhu. Ecosystem services and their economic valuation. Journal of Applied Ecology, 1999; (05): 635-640

3. Qiao Xuning, Zhang Ting, Yang Yongju, et al. Spatial flow of ecosystem services and impacts on human well-being inthe Weigan River Basin. Resource Science, 2017; 39(03): 533-544

4. Fu B J, Wang S, Su C H, et al. Linking ecosystem processes and ecosystem services. Current Opinion in Environmental Sustainability, 2013; 5(1): 4-10

5. Luo Wei, Yi Haijie, Li Hongju, et al. Spatio temporal variation of land use and its impact on ecosystem services in the Yanghe River Basin . Ecological Journal, 2017; 37(16): 5342 - 5351. 1131

6. Yi, Hoonchong, Gueneralp Burak, Filippi, Anthony M. Impacts of Land Change on Ecosystem Services in the San Antonio River Basin, Texas, from 1984 to 2010

7. Hu Jinlong. Land use change and ecological effects in Lijiang River Basin. Huazhong Agricultural University, 2016

8. Yao Yuefeng, He Chengxin, Zeng Dajuan, et al. Spatial heterogeneity of physical properties of surface soil water in Lijiang River Basin. Progress in Water Science, 2016; 27(05): 696-704

9. Zhou Ling, Zhang Li, XuJunyi et al. Analysis and prediction of land use change in the Lijiang River Basin. Study on Soil and water conservation, 2013; 20(06): $218-223+333$ 
10. Lin Peng, Chen Yudao, Xia Yuan.Types and causes of water pollution under different land use types in Lijiang River Basin[J]. Journal of Guilin University of Technology,2016; 36(03): 539—544

11. Xiang Wusheng, Li Xiankun, Ding Tao, et al. Impact of land use change on ecosystem services value in Lijiang River Basin. Study on Soil and water conservation, 2009; 16(06): 46-50+55

12. Wang Qi, Meng Jiejun, Mao Xiyan. Land use multi scenario simulation and landscape pattern change in Lijiang River Basin Based on neighborhood correlation. Geography research, 2014; 33(06): 1073 $-1084$

13. Xie Gaodi, Lu Chunxia, Leng Yunfa, et al. Evaluation of the ecological assets of the Qinghai Tibet Plateau. Journal of natural resources,2003; 18(2): 189-196

14. Lu Hui, Chen Kelong, Cao Shengkui, et al. Ecosystem services and valuation of Qinghai Lake Basin. Ecological economy, 2011; (11): 145-147

15. Jiang B0, OuYang Zhiyun, Miao Hong, et al. Evaluation of wetland ecosystem service function in Haihe River Basin. Ecological Journal, 2011; 31(08): $2236-2244$

16. Xie Gaodi, Xiao Yu, Zhen Lin, et al. Study on the ecological service value of grain production in China. Chinese Journal of ecological agriculture, 2005; 13(3):10-13

17. Müller F, Burkhard B, The indicator side of ecosystem services. Ecosystem Services, 2012; 1(1): $26-30$

18. Fu Bojie, $\mathrm{Yu}$ Dandan. Trade-off analyses and synthetic integrated method of multiple ecosystem services. Resource Science, 2016; 38(01): 1—9

19. Ma Weijing, Liu Bin, Yang Dewei, et al. Dynamic evaluation of natural capital using the ThreeDimension Ecological Footprint Model: the Jiulong River Basin in Southeast China. Resource Science, 2017; 39(05): 871—880 